\title{
Determination of Optimal Doses and Minimum Effective Concentrations of Tricaine Methanesulfonate, 2-Phenoxyethanol and Eugenol for Laboratory Managements in Nile Tilapia (Oreochromis niloticus)
}

\author{
Tirawat Rairat $^{1}$, Yu Chi ${ }^{2}$, Chia-Yu Hsieh ${ }^{2}$, Yi-Kai Liu ${ }^{2}$, Niti Chuchird ${ }^{1}$ and Chi-Chung Chou ${ }^{2,3, *(D)}$ \\ 1 Department of Fishery Biology, Faculty of Fisheries, Kasetsart University, 50 Ngamwongwan Road, \\ Ladyao, Chatuchark, Bangkok 10900, Thailand; ffistwr@ku.ac.th (T.R.); ffisntc@ku.ac.th (N.C.) \\ 2 Department of Veterinary Medicine, College of Veterinary Medicine, National Chung Hsing University, \\ Taichung 40227, Taiwan; kiwi0720@hotmail.com.tw (Y.C.); chiayuhsieh@nchu.edu.tw (C.-Y.H.); \\ kevin4100043004@gmail.com (Y.-K.L.) \\ 3 Department and Graduate Institute of Pharmacology, National Defense Medical Center, Taipei 11490, Taiwan \\ * Correspondence: ccchou@nchu.edu.tw
}

Citation: Rairat, T.; Chi, Y.; Hsieh, C.-Y.; Liu, Y.-K.; Chuchird, N.; Chou, C.-C. Determination of Optimal Doses and Minimum Effective Concentrations of Tricaine Methanesulfonate, 2-Phenoxyethanol and Eugenol for Laboratory Managements in Nile Tilapia (Oreochromis niloticus). Animals 2021, 11, 1521. https://doi.org/10.3390/ ani11061521

Academic Editor: Constanze Pietsch

Received: 29 April 2021

Accepted: 21 May 2021

Published: 24 May 2021

Publisher's Note: MDPI stays neutral with regard to jurisdictional claims in published maps and institutional affiliations.

Copyright: (c) 2021 by the authors. Licensee MDPI, Basel, Switzerland. This article is an open access article distributed under the terms and conditions of the Creative Commons Attribution (CC BY) license (https:// creativecommons.org/licenses/by/ $4.0 /)$.
Simple Summary: Fish studies often require anesthetic drugs to render the fish amenable for experimental handling and to secure animal welfare. However, the optimal dose is not always available. In this study, we determined the optimal does of three commonly used anesthetics, eugenol (EUG), tricaine methanesulfonate (MS-222), and 2-phenoxyethanol (2-PE), for induction of surgical anesthesia in marketable-size Nile tilapia, and decided on their minimum effective concentrations (MEC) in the fish serum. The results revealed that the optimal doses of EUG, MS-222, and 2-PE were 90, 300, and $900 \mathrm{ppm}$, and their MECs were 53, 70, and $263 \mu \mathrm{g} / \mathrm{mL}$, respectively. Increasing the anesthetic doses generally resulted in the shortening of the induction times, but variably affected the recovery times. In contrast, the MECs were found to be independent of the administered doses. After the dosing was stopped, the serum concentrations of anesthetics decreased rapidly, lowering by $>90 \%$ within the first hour and by $>99 \%$ after $4 \mathrm{~h}$. Our research provides practical information for a smooth fish handling and offered insights for designing researches requiring surgical anesthesia.

Abstract: Anesthetic agents are often used in fish experiments to reduce the stress and struggle and to improve animal welfare. The present study aimed to determine the optimal doses and serum minimum effective concentration (MEC) of tricaine methanesulfonate (MS-222), 2-phenoxyethanol (2-PE), and eugenol (EUG) in Nile tilapia. Twenty-one fish were immersed in three different doses of each anesthetic and the minimal dose that produce stage III anesthesia within 5 min, maintain anesthesia status for $3 \mathrm{~min}$, and recover within $5 \mathrm{~min}$ was considered the optimal dose. The serum concentrations of anesthetics immediately after the fish reached stage III anesthesia was defined as the MEC. The results revealed that the anesthetics dose-dependently shorten the induction time while the effect of doses on the recovery times were variable. The determined optimal doses for MS-222, 2-PE, and EUG were 300, 900, and 90 ppm, respectively. The MECs were 70, 263, and $53 \mu \mathrm{g} / \mathrm{mL}$, respectively, about two to four times lower than the optimal doses and were independent of the doses. After immersion stopped, the serum concentrations decreased by $>90 \%$ within the first hour and $>99 \%$ after $4 \mathrm{~h}$. Our research provides useful information for a smooth fish handling and design for researches requiring stage III anesthesia.

Keywords: anesthetics; animal welfare; MS-222; 2-phenoxyethanol; eugenol; tilapia

\section{Introduction}

To ensure animal welfare, anesthetic agents are commonly used to induce sedation and/or anesthesia in fish for many occasions such as during netting, weighing, handling, 
transportation, vaccination, blood sampling, surgery, and scientific researches [1,2]. Depending on the purpose of activity, various degrees of anesthesia stages are implemented. According to Coyle et al. [3], stages of anesthesia can be classified into four levels: stage I, sedation (characterized by reduction of motion and breathing), stage II, anesthesia (partial loss of equilibrium but still reactive to touch stimuli), stage III, surgical anesthesia (total loss of equilibrium and no reaction to touch stimuli), and stage IV, death (stop breathing and heartbeat). For invasive procedures such as surgery, drug injection, and blood sampling, in which tissue damages will occur, surgical anesthesia is advised $[3,4]$.

The recommended doses of commonly used anesthetics for teleost fish are available in the literature but with considerable variations among fish species, and the information regarding the purpose of anesthetic uses was not totally known in those reports. In general, the recommended doses for tricaine methanesulfonate (MS-222) are 25-400 ppm, for 2phenoxyethanol (2-PE) 0.25-1200 ppm, and for eugenol (EUG) 20-200 ppm [4-6]. Since conceivably the stage of anesthesia achieved may depend on the administered dose, the duration of exposure, the fish species, and the experimental conditions $[1,3,7]$, the applied anesthetic dose should take these factors into account and no single universal dose is suitable for every fish species and condition. Consequently, to improve animal welfare, the optimal dose for a given anesthetic agent should be determined case-by-case in order to avoid inadequate anesthesia stage or overdosing.

Unlike antibacterial drugs, where the relationship between pharmacokineticpharmacodynamic (PK-PD) index and therapeutic outcome exists and permits the use of PK-PD modeling to determine the optimal dosage [8], the optimal dose of the anesthetic agent is conventionally determined by the dose titration approach in which the fish are exposed to different doses of anesthetics for varying periods of time. The dose that could provide an appropriate time frame for scientific procedure with rapid induction and recovery time would be considered optimal (see the Materials and Methods section).

Nile tilapia (Oreochromis niloticus) is one of the most popular farmed fish worldwide. They have been studied extensively as a target species with respect to fish nutrition, genetics, immunology, diseases, and many others. The anesthetic agents are frequently applied in the aforementioned studies to minimize the stress and struggle, rendering them amenable to handling during invasive procedures such as blood sampling or injection. The anesthetic doses specific for tilapia have been determined by sporadic studies, for example, 120 ppm for MS-222 [9], 385-2000 ppm for 2-PE [10,11], and 20-100 ppm for EUG [9,12]. Most of these studies investigated the effects of anesthetics in the small-sized tilapia, usually below $100 \mathrm{~g}$, and the anesthetic doses suitable for relatively larger size tilapia have rarely been reported. It should be mentioned that many kinds of experiments involving surgery and the pharmacokinetic studies that are critical for the determination of optimal dosages and withdrawal time utilize adult or marketable-size fish. Similarly, the minimum effective concentration (MEC) of anesthetics in the fish serum is usually overlooked in most researches even though it can be a good circumstantial evidence supporting the rational use and proper dose of the drug. Therefore, the present study aimed to determine the optimal doses of the three commonly used anesthetic agents, namely, MS-222, 2-PE, and EUG in marketable-size Nile tilapia (about $500 \mathrm{~g}$ ) as well as the serum MEC of each anesthetic. With the use of the optimal dose, the applied anesthetic could effectively produce proper anesthesia status while minimizing any potential adverse effects and thus improving animal welfare. The information of the serum MEC, which is frequently neglected in most fish anesthetic studies, would be a piece of circumstantial evidence supporting the optimal dose usage. Overall, the results of the current study would be beneficial for reasonable uses of these three common anesthetics in multi-purpose scientific researches in fish, especially the cichlid species, when these information are otherwise unavailable. 


\section{Materials and Methods}

\subsection{Chemicals}

Reference standards of MS-222 (analytical standard grade), EUG (99\%), and sodium bicarbonate $\left(\mathrm{NaHCO}_{3}\right)$ were purchased from Sigma-Aldrich (St. Louis, MO, USA). The 2-PE (99\%) was from Acros Organics (Carlsbad, CA, USA). Acetonitrile (HPLC grade) and ethanol were from Avantor Performance Materials (Center Valley, PA, USA). Methanol (HPLC grade) was from Honeywell Burdick \& Jackson (Muskegon, MI, USA). Sodium di-hydrogen phosphate anhydrous $\left(\mathrm{NaH}_{2} \mathrm{PO}_{4}\right)$ and di-sodium hydrogen phosphate anhydrous $\left(\mathrm{Na}_{2} \mathrm{HPO}_{4}\right)$ were from Panreac Química SLU (Barcelona, Spain).

\subsection{Experimental Fish}

A total of 21 clinically healthy Nile tilapia 400-600 g in weight were obtained from a commercial fish farm in Chiayi County, Taiwan, and were kept in an outdoor concrete pond at the College of Veterinary Medicine, National Chung Hsing University, Taiwan. Each individual fish was acclimatized in a $70 \mathrm{~L}$ tank containing freshwater for 5-7 days before drug administration. The water temperature throughout the study was controlled at $28{ }^{\circ} \mathrm{C}$ by a $120 \mathrm{~W}$ aquarium heater (Tzong Yang Aquarium, Tainan, Taiwan) in an air-conditioned room. Dissolved oxygen (DO) was maintained at $\geq 5.0 \mathrm{ppm}, \mathrm{pH}$ was in the range of 7.0-8.0, and the total ammonia nitrogen was $<1.0 \mathrm{ppm}$. Temperature, $\mathrm{DO}$, and $\mathrm{pH}$ were measured by a portable water quality meter (Lutron WA-2017SD, Lutron Electronics, Coopersburg, PA, USA). The animal study was approved by the Institutional Animal Care and Use Committee of National Chung Hsing University (IACUC approval No.109-048).

\subsection{Preparation of Anesthetic Solutions}

The solutions of MS-222 (150, 225, and 300 ppm) were prepared by dissolving the MS-222 reference standard in tap water buffered with sodium bicarbonate at a ratio of 2:1 ( $\left.\mathrm{NaHCO}_{3}: \mathrm{MS}-222\right)$ [13] to maintain the water $\mathrm{pH}$ of about 7. Because of the high solubility of 2-PE at the experimented concentrations (500, 700, and 900 ppm), the reference standard of 2-PE was dispersed directly into the distilled water. In contrast, EUG was initially dissolved in 99\% ethanol at the ratio of EUG:ethanol of 1:9 [14] before being further diluted in the distilled water to obtain the predetermined concentrations $(70,80$, and $90 \mathrm{ppm})$. Solutions of all anesthetic agents were freshly prepared before use. Note that the concentration unit of all anesthetic agents in this study was part per million (ppm) (mg/L).

\subsection{Determination of the Optimal Doses Following Single Immersion Administration}

For the purpose of the study, the optimal dose is defined as the minimal dose that could induce stage III anesthesia within $5 \mathrm{~min}$, maintain stage III anesthesia for $3 \mathrm{~min}$, and has a recovery time of less than $5 \mathrm{~min}$ after the fish is put back into the recovery tank [5,7]. These criteria are chosen based on the timeframe the anesthetic agent could provide for multiple scientific procedures and general activities. To determine the optimal anesthetic doses, the dose titration approach with a cross-over design was used. Specifically, a single fish would be sequentially exposed to the three different doses of the same anesthetic agent with a 1-week wash out period between any two consecutive doses.

Twenty-one Nile tilapia were randomly distributed into one of the three groups, namely, MS-222, 2-PE, and EUG groups ( $n=7$ for each anesthetic). Taking the MS-222 group as an example, each fish was immersed with a given dose of MS-222 (150, 225, and $300 \mathrm{ppm}$ ) in a $10 \mathrm{~L}$ tank until stage III anesthesia was achieved (the induction phase). Then, the fish were monitored for another $3 \mathrm{~min}$ for the anesthesia status (the maintenance phase) before they were put back into a $70 \mathrm{~L}$ recovery tank (the recovery phase). The water temperature during the induction and recovery phases was controlled at $28^{\circ} \mathrm{C}$. Similarly, the doses of 500, 700, and 900 ppm 2-PE were tested on another 7 fish, and the doses of 70, 80, and 90 ppm EUG were tested, as well. The induction and recovery times of all groups were recorded. The fish that could not reach stage III anesthesia within a maximum observation period of $13 \mathrm{~min}$ were excluded from the statistical analysis. Note that the 
experimental doses were selected based on our preliminary results with 2 tilapia for each drug at their recommended doses of 150 ppm for MS-222, 500 ppm for 2-PE, and 60 for ppm EUG [3]. Higher doses were employed for subsequent testing because these preliminary doses failed to induce anesthesia within $3 \mathrm{~min}$ while some were successful within $5 \mathrm{~min}$.

\subsection{Determination of the MECs and the Serum Concentration-Time Profiles}

Once the fish attained stage III anesthesia, they were removed from the water and the blood $(0.1 \mathrm{~mL})$ was collected from the caudal vessels using a $1 \mathrm{~mL}$ syringe with $22 \mathrm{G}$ needle without anticoagulant at $0,0.25,0.5,1,2$, and $4 \mathrm{~h}$. The blood samples were allowed to clot at room temperature and centrifuged at $3500 \mathrm{rpm}(2191 \times g ; \mathrm{KN}-70$, Kubota, Japan) for $10 \mathrm{~min}$; the supernatants were collected and kept at $-70{ }^{\circ} \mathrm{C}$ until analysis. The procedures of HPLC analysis are described below.

The serum concentration immediately after the fish reached stage III anesthesia $(t=0 \mathrm{~h})$ was considered the MEC. To avoid confusion between the concentration of anesthetics in the water and those in the serum, the term ppm was used for the water concentration (anesthetic dose) while $\mu \mathrm{g} / \mathrm{mL}$ was used for the serum concentration.

\subsection{Sample Preparation and HPLC Analysis of Anesthetics in the Fish Serum}

The serum samples $(50 \mu \mathrm{L})$ were mixed with $150 \mu \mathrm{L}$ of acetonitrile containing $0.1 \%$ formic acid in a $0.5 \mathrm{~mL}$ microcentrifuge tube and centrifuged at $3500 \mathrm{rpm}(2191 \times g)$ for $10 \mathrm{~min}$. The supernatant was transferred into a new $0.5 \mathrm{~mL}$ microcentrifuge tube and the acetonitrile with $0.1 \%$ formic acid was added to obtain a final volume of $200 \mu \mathrm{L}$. At the final step, $60 \mu \mathrm{L}$ of the supernatant containing MS-222 was mixed with $140 \mu \mathrm{L}$ of the phosphate buffer (10 $\mathrm{mM} \mathrm{NaH}_{2} \mathrm{PO}_{4}-\mathrm{Na}_{2} \mathrm{HPO}_{4}, \mathrm{pH}$ 5). For the samples containing 2-PE and EUG, 68 and $90 \mu \mathrm{L}$ of the supernatants were mixed with 132 and $110 \mu \mathrm{L}$ of the phosphate buffer, respectively. All samples were filtered through $0.2 \mu$ m nylon syringe filters prior to the HPLC analyses.

The HPLC system consisted of a pump (1260 Infinity II, Agilent Technologies, Santa Clara, CA, USA), a UV-visible detector (1260 Infinity II, Agilent Technologies, Santa Clara, CA, USA), and a C-18 column sized $150 \times 4.6 \mathrm{~mm}$ (Apollo, Hichrom, UK) for the MS222 and $250 \times 4.6 \mathrm{~mm}$ (Mightysil, Kanto, Japan) for the 2-PE and EUG analyses. The mobile phases were mixtures of acetonitrile, methanol, and the phosphate buffer $(10 \mathrm{mM}$ $\mathrm{NaH}_{2} \mathrm{PO}_{4}-\mathrm{Na}_{2} \mathrm{HPO}_{4}, \mathrm{pH}$ ) at a ratio of 30:0:70, 17:17:66, and 45:0:55 $v / v$ for the analysis of MS-222, 2-PE, and EUG, respectively. The detection wavelengths were 220, 218, and $200 \mathrm{~nm}$; the flow rate was $1 \mathrm{~mL} / \mathrm{min}$ and the injection volume was $50 \mu \mathrm{L}$.

To establish the matrix calibration curves for quantification of the anesthetics, the reference standard was spiked into the blank fish serum at final concentrations of 100, $500 \mathrm{ng} / \mathrm{mL}, 1,5,10$, and $50 \mu \mathrm{g} / \mathrm{mL}$, then extracted and analyzed by the HPLC method described above. The weighting factor of $1 / x^{2}$ was applied to improve the accuracy at the lower concentrations of the calibration curve. The limit of detection (LOD) and the limit of quantification (LOQ) were calculated by $3.3 \times \sigma / S$ and $10 \times \sigma / S$, respectively ( $\sigma$ is the standard deviation of the $y$-intercept of the regression line, $S$ is the slope of the calibration curve).

\subsection{Statistical Analysis}

Statistical analysis was performed using IBM SPSS Statistics version 25 software (IBM Corporation, Armonk, NY, USA). The differences of the induction times, recovery times, and MECs among the three doses were analyzed by one-way within-subjects (repeated measures) ANOVA. The differences were considered significant if $p$-value $<0.05$.

\section{Results}

\subsection{HPLC Method Validations for Quantification of Anesthetics}

The matrix calibration curves were linear over the range of $100 \mathrm{ng} / \mathrm{mL}$ to $50 \mu \mathrm{g} / \mathrm{mL}$ for all three anesthetics with the weighted $r^{2}$ of $0.9968,0.9938$, and 0.9891 for MS-222, 2-PE, 
and EUG, respectively. The LODs were 153,47 , and $89 \mathrm{ng} / \mathrm{mL}$, and the LOQs were 463 , 143 , and $269 \mathrm{ng} / \mathrm{mL}$, respectively. The extraction recoveries were $88-108 \%, 100-110 \%$, and $80-97 \%$, respectively. The accuracies were $95.7-96.6 \%, 96.7-97.8 \%$, and $96.6-98.5 \%$, the intra-day precisions were $0.23-1.63 \%, 0.15-4.61 \%$, and $0.22-2.70 \%$, and the inter-day precisions were $0.78-1.91 \%, 0.45-3.01 \%$, and $0.58-2.81 \%$, respectively, for MS-222, 2-PE, and EUG. The retention times were 10.7, 11.5, and 11.4 min (Figure 1).
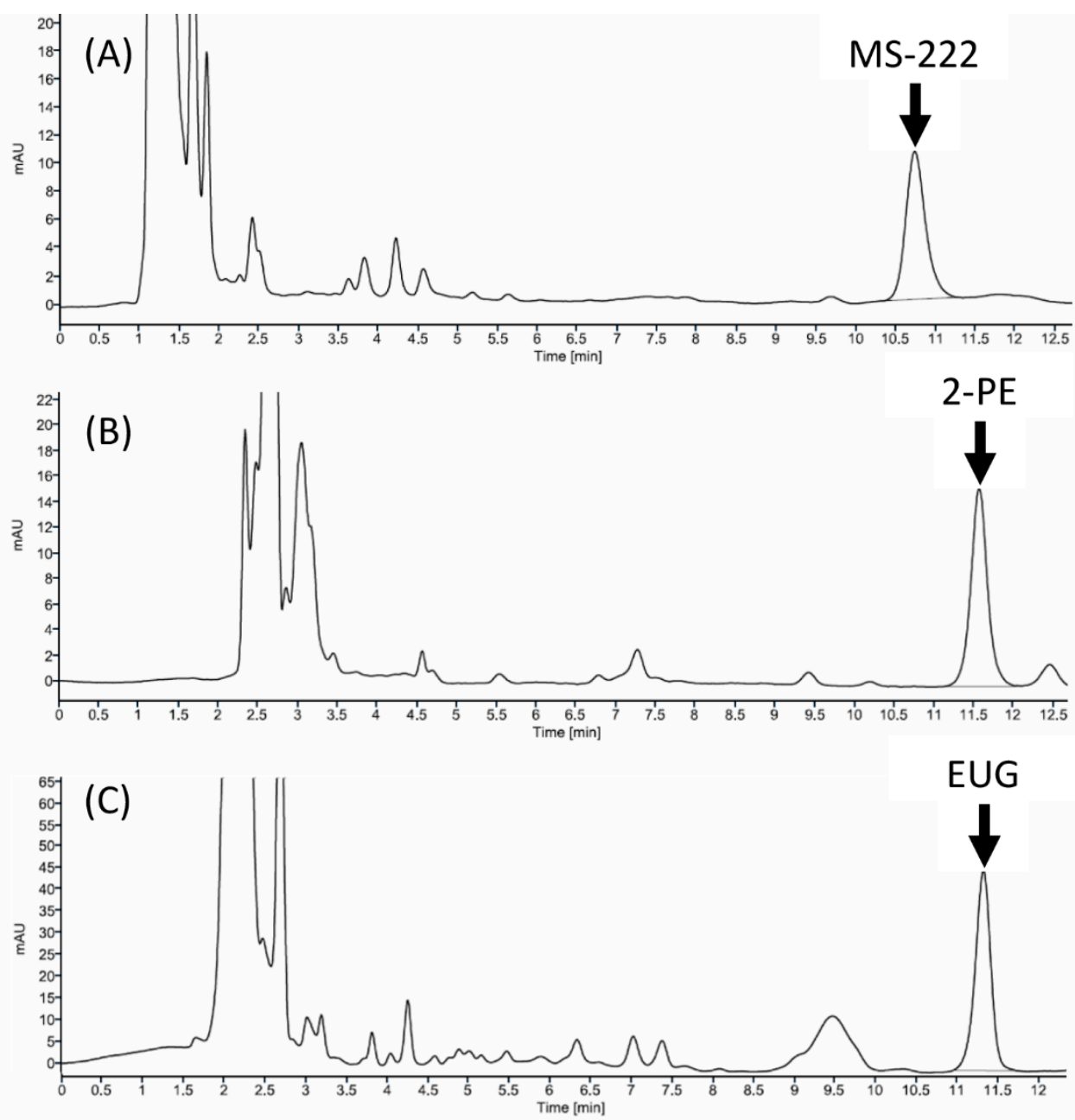

Figure 1. The representative chromatograms of $1 \mu \mathrm{g} / \mathrm{mL}$ reference standard of anesthetics in tilapia serum. The mobile phases consisted of acetonitrile, methanol, and the phosphate buffer (10 mM NaH2PO4-Na2HPO4, pH 5) at a ratio of: (A) 30:0:70 $v / v$ for MS-222 (UV $200 \mathrm{~nm}$ ); (B) 17:17:66 v/v for 2-PE (UV $218 \mathrm{~nm}$ ); (C) 45:0:55 v/v for EUG (UV $200 \mathrm{~nm}$ ).

\subsection{Determination of the Optimal Doses Following Single Immersion Administration.}

The selection of the optimal dose was based on the behavior response to the anesthetic agents mentioned above. All fish passed the criteria for recovery time (in less than $5 \mathrm{~min}$ ) on the three doses (Table 1). However, only the highest dose of each anesthetic (i.e., MS-222 300 ppm, 2-PE 900 ppm, and EUG 90 ppm) fulfilled the criteria of induction time (less than $5 \mathrm{~min}$ ) and maintaining stage III anesthesia for $3 \mathrm{~min}$ in all fish. Thus, the 300, 900, and 90 ppm were considered optimal doses for MS-222, 2-PE, and EUG, respectively. 


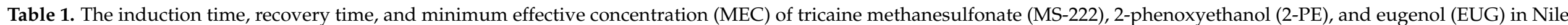
tilapia at $28^{\circ} \mathrm{C}$ following single immersion administrations $(n=7){ }^{\mathrm{A}}$.

\begin{tabular}{|c|c|c|c|c|c|c|c|}
\hline Anesthetic Drug & Dose (ppm) & Induction Time (s) & $\begin{array}{c}\text { Number of Fish } \\
\text { That Had Induction } \\
\text { Time }<5 \text { min }\end{array}$ & $\begin{array}{l}\text { Number of Fish That Could } \\
\text { Be Maintained in Stage III } \\
\text { Anesthesia for } 3 \mathrm{~min}\end{array}$ & Recovery Time (s) & $\operatorname{MEC}(\mu \mathrm{g} / \mathrm{mL})^{B}$ & $\begin{array}{l}\text { Grand Mean of } \\
\operatorname{MEC}(\mu \mathrm{g} / \mathrm{mL})\end{array}$ \\
\hline \multirow[t]{2}{*}{ MS-222 } & $150^{C}$ & $488.60 \pm 125.38^{a}$ & $2 / 7$ & $4 / 7$ & $14.80 \pm 15.01^{\mathrm{a}}$ & $64.74 \pm 12.84^{\mathrm{a}}$ & \multirow{2}{*}{$70.40 \pm 22.06$} \\
\hline & 300 & $153.43 \pm 48.38^{b}$ & $7 / 7$ & $7 / 7$ & $47.00 \pm 11.00^{b}$ & $66.36 \pm 21.62^{a}$ & \\
\hline \multirow[t]{3}{*}{ 2-PE } & $500^{\mathrm{D}}$ & $547.33 \pm 173.02^{a}$ & $0 / 7$ & $3 / 7$ & $81.57 \pm 54.06^{\mathrm{a}}$ & $245.87 \pm 71.24^{a}$ & \multirow{3}{*}{$262.57 \pm 90.33$} \\
\hline & 700 & $382.57 \pm 57.52^{\mathrm{a}}$ & $0 / 7$ & $7 / 7$ & $132.57 \pm 45.94^{\mathrm{a}}$ & $267.85 \pm 82.21^{a}$ & \\
\hline & 900 & $256.00 \pm 47.72^{\mathrm{a}}$ & $7 / 7$ & $7 / 7$ & $113.57 \pm 32.58^{\mathrm{a}}$ & $264.46 \pm 114.59^{\mathrm{a}}$ & \\
\hline \multirow[t]{3}{*}{ EUG } & 70 & $236.71 \pm 78.25^{a}$ & $4 / 7$ & $7 / 7$ & $60.57 \pm 19.54^{a}$ & $41.97 \pm 17.82^{\mathrm{a}}$ & \multirow{3}{*}{$53.41 \pm 18.36$} \\
\hline & 80 & $223.00 \pm 68.91^{a}$ & $5 / 7$ & $7 / 7$ & $61.71 \pm 25.74^{\mathrm{a}}$ & $65.07 \pm 18.23^{b}$ & \\
\hline & 90 & $164.71 \pm 21.58^{a}$ & $7 / 7$ & $7 / 7$ & $54.14 \pm 19.57^{\mathrm{a}}$ & $53.19 \pm 12.74^{a b}$ & \\
\hline
\end{tabular}

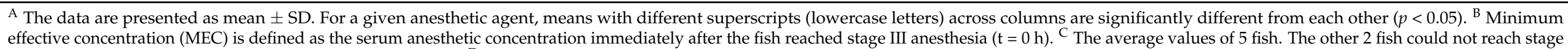
III anesthesia despite being exposed to MS-222 up to $13 \mathrm{~min}$. ${ }^{\mathrm{D}}$ The average values of 3 fish. The other 4 fish could not reach stage III anesthesia despite being exposed to 2 -PE up to 13 min. 
During the induction phase, the fish showed sign of lower opercula ventilation rate, loss of equilibrium, and expected loss of reaction to touch stimuli. During the recovery process, the fish rapidly resumed normal opercula movement and consciousness as well as reactions to touch stimuli. Increasing the anesthetic doses resulted in the shortening of the induction time in a dose-dependent manner; however, the differences were statistically significant only in the MS-222 group $(p<0.05)$ (Table 1$)$. In contrast, the effects of the doses on the recovery times were variable. Whereas the prolongation of the recovery time with increasing doses could be demonstrated in the MS-222 group $(p<0.05)$, no dose-dependency was observed in the other two anesthetic groups.

\subsection{Determination of the MECs and the Serum Concentration-Time Profiles.}

For each anesthetic agent, despite different immersing dose levels, the MECs to reach stage III anesthesia were similar among anesthetics (Table 1). Because the MECs of the three doses were either not significantly different (MS-222 and 2-PE groups) or not showing dose-dependency (EUG group), the MECs from different doses were combined into a single grand mean and the MECs for MS-222, 2-PE, and EUG were $70.40 \pm 22.06,262.57 \pm 90.33$, and $53.41 \pm 18.36 \mu \mathrm{g} / \mathrm{mL}$, respectively.

The serum concentration time profiles of the three anesthetics at the three doses after the termination of the bath administration are presented in Figure 2. Following the transfer of the fish into the recovery tanks, the serum concentration of the three anesthetics revealed a multi-exponential decay with rapid elimination. All three anesthetics decreased by more than $90 \%$ within the first hour, and at the last blood sampling time point $(\mathrm{t}=4 \mathrm{~h})$, only $0.2-0.5 \%$ of MS-222 remained in the serum. Similarly, only $0.3-0.5$ and $0.9-1.1 \%$ of $2-\mathrm{PE}$ and EUG remained in the serum after $4 \mathrm{~h}$ (data not shown). At the optimal doses, the highest serum concentration was observed in the 900 ppm 2-PE groups, followed by the 90 ppm EUG and the 300 ppm MS-222 group (Figure 3); the serum concentrations at 4 h were 1.01, 0.59 , and $0.13 \mu \mathrm{g} / \mathrm{mL}$, respectively. 

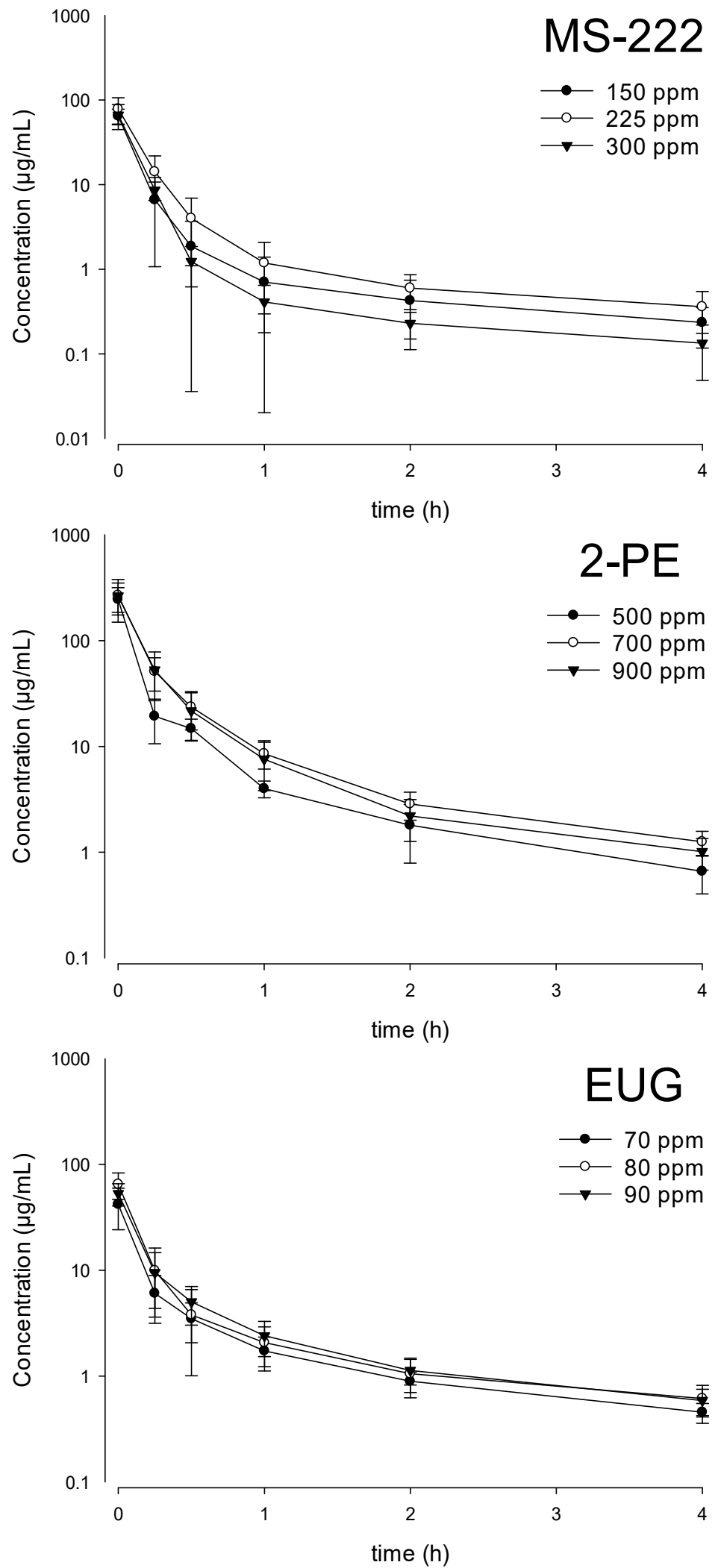

Figure 2. Serum concentration time profile (mean \pm SD) of tricaine methanesulfonate (MS-222), 2-phenoxyethanol (2-PE), and eugenol (EUG) in Nile tilapia during the recovery phase following immersion at 3 different doses at $28^{\circ} \mathrm{C}(n=7)$. 


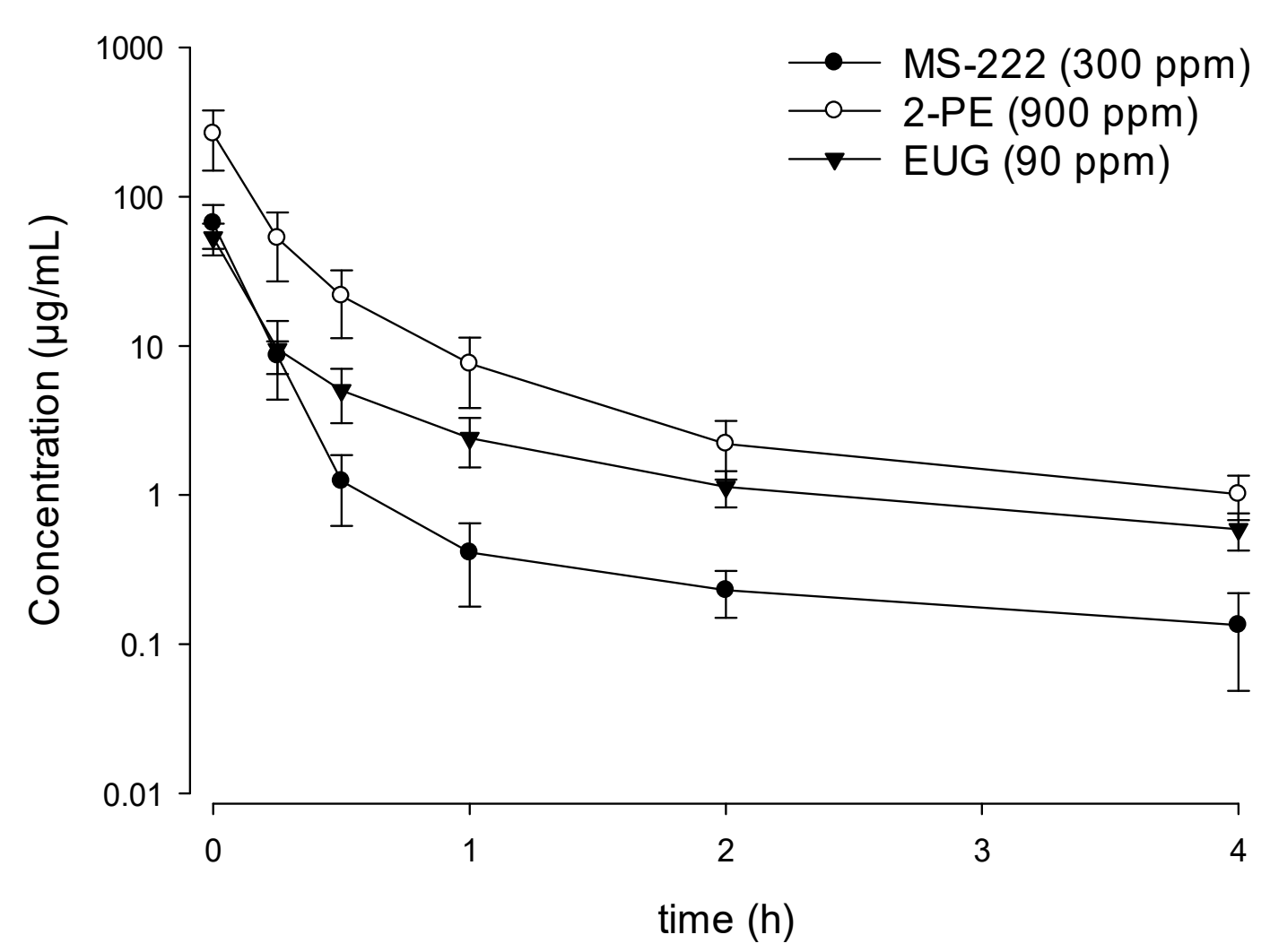

Figure 3. Serum concentration time profile (mean $\pm \mathrm{SD}$ ) of tricaine methanesulfonate (MS-222), 2-phenoxyethanol (2-PE), and eugenol (EUG) in Nile tilapia during the recovery phase following immersion at the optimal doses at $28^{\circ} \mathrm{C}(n=7)$.

\section{Discussion}

"Can fish feel pain?" is an ongoing debate among researchers as many have claimed that fish do have sensation of pain while others disagree [15-18]. For the sake of animal welfare, it is wise to err on the safe side such that the use of anesthetics in fish experiments, especially for invasive procedures, is encouraged whenever applicable [1,2].

Similar to many drugs, the effectiveness of anesthetic agents in aquatic animals depends on several factors such as the fish species [19-21] and the rearing environment, especially the water temperature [19,22-25]. Therefore, in order to maximize a drug's efficacy while minimizing its toxicity, an optimal dose for a given fish species in a specified environment is preferred. However, the definition of an optimal dose may vary depending on different research purposes. For example, most studies referred to the optimal dose as the lowest dose that could produce anesthesia with an induction time within $3 \mathrm{~min}$ and a recovery time within 5 min $[7,21,26-28]$. In contrast, other researchers may use an induction time of less than 3-5 $\mathrm{min}$ [20] or 5-10 $\mathrm{min} \mathrm{[5]} \mathrm{and} \mathrm{a} \mathrm{recovery} \mathrm{time} \mathrm{of} \mathrm{less}$ than $10 \mathrm{~min}[19,20,25]$. Our preliminary study revealed that Nile tilapia at this size could not be anesthetized within 3 min even though the maximum recommended doses were applied [3]. Consequently, we decided to use an induction time of less than $5 \mathrm{~min}$ as the criteria for the optimal dose, as opposed to the more commonly used $3 \mathrm{~min}$. The general criterion of a 5-minute recovery time was chosen because Nile tilapia could quickly resume their response to stimuli after the cessation of anesthetics. Please refer to the Materials and Methods section for the method of choosing the optimal dose in the present study. Based on the aforementioned criteria, the determined optimal doses of the three anesthetics were generally higher than those found in the literature regardless of fish species, body weight, or experimental conditions. For instance, the optimal doses of MS-222 were reported to be $75 \mathrm{ppm}$ for Senegalese sole [26], 100-125 ppm for marbled spinefoot [27], $120 \mathrm{ppm}$ for Nile tilapia fry [9], $140 \mathrm{ppm}$ for spotted sea bass [25], and 75-200 ppm for four tropical aquarium fishes [21]. Similarly, the optimal doses of 2-PE were $167 \mathrm{ppm}$ for white sea bream and 
sharp snout sea bream [20], 300-350 ppm for European sea bass and 300-450 ppm for gilthead sea bream [19], 400 ppm for marbled spinefoot [27], and 600 ppm for Senegalese sole [26]. The optimal doses of EUG were $20 \mathrm{ppm}$ for Nile tilapia fry [9], $50 \mathrm{ppm}$ for red tilapia juvenile [12], $60 \mathrm{ppm}$ for spotted sea bass [25], and $80 \mathrm{ppm}$ for freshwater angelfish [28]. The reason why the current results are almost always greater than the other studies might be mainly due to the species differences, as tilapia usually requires higher anesthetic doses when compared to other fishes [3,6,7]. The physiological characteristics responsible for the mechanism are not well understood, but might be related to the greater intrinsic capability of tilapia to metabolize and/or excrete xenobiotics and being a warmwater fish that in general metabolically more active than the cold-water fish species [22,23]. The influence of body weight on the anesthetic effects is even less clear. It is interesting to note that the marketable-size tilapia (from the current study) required higher doses for anesthetic induction when compared to the fry or juvenile tilapia [9-12]. Whether or not the small-sized fish has faster absorption and/or lower MEC than the bigger fish remain to be elucidated. Since the drug effect is also dependent on the experimental conditions and environmental factors, direct comparison and interpretations among different studies should be performed with caution $[20,22-24,26]$. Among the anesthetics evaluated, EUG showed the lowest effective concentration while 2-PE was the highest. The EUG worked at a concentration three times lower than MS-222 and 10 times lower than 2-PE. A similar phenomenon of smaller effective EUG concentrations has been reported in several other species, with doses about two to six times smaller than MS-222 in spotted sea bass [25], hickory shad [29], and Nile tilapia [9], and doses 4 to 20 times smaller than 2-PE in hickory shad [29], shabout [30], and European sea bass [31]. From the economic aspect, although EUG is more expensive than 2-PE calculated by weight, the EUG is the cheapest of the three anesthetics used in the present study calculated by every $10 \mathrm{~L}$ of each anesthetic at optimal concentrations (USD 20 for MS-222, USD 0.8 for 2-PE, and USD 0.6 for EUG, based on the price from the sources listed in the Materials and Methods section). With the lowest effective dosage, EUG not only was the most economic choice, but also the one that produces lowest pollution by weight for the environment, making it a desirable choice from a practical viewpoint.

The decrease in the induction time as the anesthetic dose increases could be reasonably expected. At a higher dose, the drug reaches the threshold concentration (the MEC) earlier, and thus produces the pharmacological action (anesthesia) sooner. In fact, this is one of the most consistent outcomes in studies with different anesthetic doses, including the three agents used $[9,11,27,29,32]$. The lack of statistically significant differences in the induction times at different dosages of the EUG and 2-PE groups in the present study was likely due to the high variation in the individual fish response and the relatively small differences between the experimental dose levels to show statistically different outcomes. Nevertheless, the trends of dose-dependent shortening in the induction times of the two drugs could still be acknowledged. On the other hand, the effects of increasing doses on the recovery time were more variable. Some studies found more sensible direct relationships (increasing the dose prolongs the recovery time) for MS-222 in Nile tilapia [the current study], Nile tilapia fry [9], goldfish [32], zebrafish, guppy, discus [21], and spotted sea bass [25]; for 2-PE in hybrid tilapia juvenile [11], European sea bass [31], goldfish [32], and hickory shad [29]; and for EUG in Nile tilapia fry [9], red tilapia juvenile [12], and spotted sea bass [25]; while other studies, albeit less common, reported the reverse trend (increasing the dose leading to the shortening of the recovery time). This seemingly counterintuitive outcome is attributed to the fact that the duration of the anesthetic exposure is usually also be reduced at a higher dose (thus a shortened induction time) such that lower drug uptake and faster removal is expected [19]. The specific examples include MS-222 in common carp [33], Senegalese sole [26], green swordtail [21], and hickory shad [29]. On the same note, there were studies that found no clear correlation between the anesthetic doses and the recovery time; specific examples also include MS-222 [27,34], 2-PE [the current study and 19,26,27], and EUG [the current study and 28,29,31]. The absence of significant 
differences in the recovery times at different dosages of the EUG and 2-PE groups in the present study likely reflected the real lack of significance at the tested doses as the dosedependent responses were not observed. This phenomenon might be understandable from the pharmacokinetic principle assuming the first-order kinetics of drug elimination: the higher the dose, the faster the elimination rate [35]. Consequently, the elimination half-life of the drug did not change significantly with dose (dose-independent), nor did the recovery time. Overall, the effect of anesthetic doses on the recovery time depends on the interplay between the pharmacokinetic and pharmacodynamic properties of a drug, which might also be confounded by experimental and environmental conditions. It is not clear which physiological and biochemical differences characteristic to each fish species contributed to the various relationship between the doses and the recovery time, but this is certainly worth further investigation.

The fact that fish immersed in higher doses required shorter exposure time to reach stage III anesthesia most likely explained the similar MECs across the three different doses regardless of anesthetics. Despite the high inter-individual variability, the average MECs of MS-222 $(70 \mu \mathrm{g} / \mathrm{mL})$ and EUG $(53 \mu \mathrm{g} / \mathrm{mL})$ were lower than that of the 2-PE $(263 \mu \mathrm{g} / \mathrm{mL})$, suggesting lesser potency of 2-PE in inducing stage III anesthesia in Nile tilapia. When MECs of different fish species were compared, the MEC of MS-222 in Nile tilapia was four times higher than that in the Atlantic salmon $(70 \mathrm{vs.} 16 \mu \mathrm{g} / \mathrm{mL})$ [36] and 24 times higher (53 vs. $2.2 \mu \mathrm{g} / \mathrm{mL}$ ) than the MEC of EUG in the Japanese flounder [37]. These findings were in agreement with the general need for higher optimal doses in Nile tilapia compared to other fish species, as previously mentioned [3,6,7]. These data once more highlight the necessity of obtaining specific information beforehand on the choice of anesthetic and its optimal dose for proper handling of the fish and getting trustful research results.

Following the transfer of the Nile tilapia to the recovery tanks, the serum concentrations of the three anesthetic agents declined rapidly (and multi-exponentially) with a similar trend. To date, there is no information available for the serum/plasma half-lives of these three agents in Nile tilapia. Unfortunately, based on the nature of the drug (an anesthetic agent) and the limited $4 \mathrm{~h}$ sampling time, we could not reasonably assure whether the sampling length surpassed the distribution phases and reached the elimination phases long enough, and therefore the half-lives were not calculated or reported in the current study. The published serum/plasma half-lives of MS-222, which were $1.7 \mathrm{~min}$ (distribution half-life) in the Atlantic salmon [36] and $56 \mathrm{~min}$ in the spiny dogfish [38], were found to be much shorter than the half-lives of EUG, which were $12.1 \mathrm{~h}$ in the rainbow trout [39] and $19.8 \mathrm{~h}$ in the grass carp [40], whereas the serum/plasma half-life of 2-PE in fish has not been reported thus far. In contrast, the muscle half-lives of MS-222, 2-PE, and EUG in tilapia were less different and reported to be $53.5,147.8$, and $52.5 \mathrm{~min}$, respectively [41]. While the current design prevented us from providing confident estimation of serum half-lives and other PK parameters, it appeared that based on the percentage of the remaining drug at the last time point $(t=4 \mathrm{~h})$ relative to the initial concentration $(t=0 \mathrm{~h})$, the elimination of MS-222 at the optimal dose was very rapid and more rapid than the EUG and 2-PE. Although the elimination half-lives of the three anesthetics could not be accurately calculated (as mentioned above) due to the lack of anesthetic half-life information in this fish, we provisionally derived the half-lives from the slopes of the concentration-time curve based on the last three time points, and the estimated half-lives for MS-222, 2-PE, and EUG in Nile tilapia at their optimal doses were all around $1.5 \mathrm{~h}$ (data not shown). This information could serve as the first estimation of the time scale of the half-lives of these commonly used anesthetic agents. The apparently shorter terminal half-lives of anesthetic drugs in Nile tilapia compare to other teleosts $[39,40]$ was in agreement with the higher optimal doses re-quired to attain the stage III anesthesia status and might be related to the higher met-abolic rate of this warm-water species. It should also be mentioned that regarding the effect of the rearing temperature, increase water temperature generally accelerate both induction time and recovery time, no matter in cold-water fish such as Atlantic cod [22], warm-water fish such as marbled rabbitfish [24], or eurythermal fish such as Eu-ropean 
sea bass and gilthead sea bream [19]. However, this conclusion could not be applied in every situation as Atlantic halibut showed longer recovery time in warmer water [23] and spotted sea bass even exhibited dose-dependent temperature effects [25]. The influence of water temperature on anesthetic action is possibly species- and drug-specific such that the general assumption of faster induction and recovery pro-cesses at higher temperature should be treated with caution.

In short, the current study provides the optimal doses of MS-222, 2-PE, and EUG for multi-purpose uses in Nile tilapia experimented at $28^{\circ} \mathrm{C}$ that require stage III anesthesia such as surgery, blood collection, and various routes of drug administrations. The results also indicated that tilapia often require higher anesthetic doses compared to other fish species, which was likely related to the higher MECs required to attain the same level of anesthesia. The results could possibly be representative for fishes of various genus levels in which such information were rare or otherwise unavailable.

\section{Conclusions}

The optimal doses to induce stage III anesthesia within $5 \mathrm{~min}$, maintain anesthesia status for $3 \mathrm{~min}$ and recover within $5 \mathrm{~min}$, were determined for the first time for MS-222 (300 ppm), 2-PE (900 ppm), and EUG (90 ppm) in marketable-size (about 500 g) Nile tilapia cultured at $28{ }^{\circ} \mathrm{C}$. The rarely reported MECs $(70,263$, and $53 \mu \mathrm{g} / \mathrm{mL}$, respectively) were two to four times lower than the optimal doses and were found to be independent of the anesthetic doses, a novel discovery. The serum elimination half-lives of the three anesthetics at their optimal doses were provisionally provided. The current study highlighted the benefits of obtaining information specific to the anesthetic and its optimal dose beforehand. The effect of environmental factors such as temperature and salinity on the optimal doses and MECs of anesthetic agents is worth future investigation.

Author Contributions: Conceptualization, T.R., Y.C., and C.-C.C.; investigation, Y.C. and Y.-K.L.; methodology, Y.C. and Y.-K.L.; validation, Y.C.; formal analysis, T.R. and N.C.; resources, C.-Y.H. and C.-C.C.; data curation, T.R. and Y.C.; writing-original draft preparation, T.R.; writing-review and editing, T.R. and C.-C.C.; project administration, C.-C.C. All authors have read and agreed to the published version of the manuscript.

Funding: This research was funded by Ministry of Science and Technology, Taiwan, grant number: MOST 109-2313-B-005 -015-MY3.

Institutional Review Board Statement: The animal study was approved by the Institutional Animal Care and Use Committee of National Chung Hsing University (IACUC approval No.109-048).

Informed Consent Statement: Not applicable.

Data Availability Statement: The data presented in this study are available on request from the corresponding author.

Acknowledgments: The authors would like to thank Gao Zheng farm, Chiayi County, Taiwan, for kindly supplying us the tilapia.

Conflicts of Interest: The authors declare no conflict of interest.

\section{References}

1. Zahl, I.H.; Samuelsen, O.; Kiessling, A. Anaesthesia of farmed fish: Implications for welfare. Fish. Physiol. Biochem. 2012, 38 , 201-218. [CrossRef] [PubMed]

2. Martins, T.; Valentim, A.; Pereira, N.; Antunes, L.M. Anaesthetics and analgesics used in adult fish for research: A review. Lab. Anim. 2019, 53, 325-341. [CrossRef] [PubMed]

3. Coyle, S.D.; Durborow, R.M.; Tidwell, J.H. Anesthetics in Aquaculture; SRAC Publication No. 3900; Southern Regional Aquaculture Center: Stoneville, MS, USA, 2004.

4. Sneddon, L.U. Clinical anesthesia and analgesia in fish. J. Exot. Pet. Med. 2012, 21, 32-43. [CrossRef]

5. Neiffer, D.L.; Stamper, M.A. Fish sedation, anesthesia, analgesia, and euthanasia: Considerations, methods, and types of drugs. ILAR J. 2009, 50, 343-360. [CrossRef]

6. Priborsky, J.; Velisek, J. A review of three commonly used fish anesthetics. Rev. Fish. Sci. Aquac. 2018, 26, 417-442. [CrossRef] 
7. Ross, L.G.; Ross, B. Anaesthetic and Sedative Techniques for Aquatic Animals, 3rd ed.; Blackwell Publishing: Oxford, UK, 2008.

8. Rairat, T.; Hsieh, C.Y.; Thongpiam, W.; Chou, C.C. Pharmacokinetic-pharmacodynamic modelling for the determination of optimal dosing regimen of florfenicol in Nile tilapia (Oreochromis niloticus) at different water temperatures and antimicrobial susceptibility levels. J. Fish. Dis. 2019, 42, 1181-1190. [CrossRef]

9. Charoendat, U.; Areechon, N.; Srisapoome, P.; Chantasart, D. Efficacy of synthetic eugenol as an anesthetic for Nile tilapia (Oreochromis niloticus Linn.). Kasetsart. J. 2009, 43, 132-140.

10. Auperin, B.; Baroiller, J.-F.; Ricordel, M.-J.; Fostier, A.; Prunet, P. Effect of confinement stress on circulating levels of growth hormone and two prolactins in freshwater-adapted tilapia (Oreochromis niloticus). Gen. Comp. Endocrinol. 1997, 108, 35-44. [CrossRef]

11. Tengjaroenkul, B.; Pimpukdee, K.; Tengjaroenkul, U. Anesthetic dosages of quinaldine sulfate and 2-phenoxyethanol for induction, maintenance and lethal dose 50 in the juvnile hybrid tilapia. KKU. Res. J. 2004, 9, 49-58. (in Thai).

12. Rucinque, D.S.; Polo, G.; Borbón, J.; González Mantilla, J.F. Anesthetic use of eugenol and benzocaine in juveniles of red tilapia. Rev. Colomb. Cienc. Pecu. 2017, 30, 60-66. [CrossRef]

13. Topic Popovic, N.; Strunjak-Perovic, I.; Coz-Rakovac, R.; Barisic, J.; Jadan, M.; Persin Berakovic, A.; Sauerborn Klobucar, R. Tricaine methane-sulfonate (MS-222) application in fish anaesthesia. J. Appl. Ichthyol. 2012, 28, 553-564. [CrossRef]

14. Posner, L.P.; Harms, C.A.; Smith, S.A. Sedation, Anesthesia, Analgesia and Euthanasia. In Fish Diseases and Medicine; Smith, S.A., Ed.; CRC Press: Boca Raton, FL, USA, 2019; pp. 283-304.

15. Braithwaite, V.A.; Ebbesson, L.O.E. Pain and stress responses in farmed fish. Rev. Sci. Technol. 2014, 33, 245-253. [CrossRef] [PubMed]

16. Rose, J.D.; Arlinghaus, R.; Cooke, S.J.; Diggles, B.K.; Sawynok, W.; Stevens, E.D.; Wynne, C.D.L. Can fish really feel pain? Fish Fish. 2014, 15, 97-133. [CrossRef]

17. Chatigny, F. The controversy on fish pain: A veterinarian's perspective. J. Appl. Anim. Welf. Sci. 2019, 22, 400-410. [CrossRef] [PubMed]

18. Michel, M. Fish and microchips: On fish pain and multiple realization. Philos. Stud. 2019, 176, 2411-2428. [CrossRef]

19. Mylonas, C.C.; Cardinaletti, G.; Sigelaki, I.; Polzonetti-Magni, A. Comparative efficacy of clove oil and 2-phenoxyethanol as anesthetics in the aquaculture of European sea bass (Dicentrarchus labrax) and gilthead sea bream (Sparus aurata) at different temperatures. Aquaculture 2005, 246, 467-481. [CrossRef]

20. Tsantilas, H.; Galatos, A.D.; Athanassopoulou, F.; Prassinos, N.N.; Kousoulaki, K. Efficacy of 2-phenoxyethanol as an anaesthetic for two size classes of white sea bream, Diplodus sargus L. and sharp snout sea bream, Diplodus puntazzo C. Aquaculture 2006, 253, 64-70. [CrossRef]

21. Chambel, J.; Pinho, R.; Sousa, R.; Ferreira, T.; Baptista, T.; Severiano, V.; Mendes, S.; Pedrosa, R. The efficacy of MS-222 as anaesthetic agent in four freshwater aquarium fish species. Aquacult. Res. 2015, 46, 1582-1589. [CrossRef]

22. Zahl, I.H.; Kiessling, A.; Samuelsen, O.B.; Hansen, M.K. Anaesthesia of Atlantic cod (Gadus morhua)-Effect of pre-anaesthetic sedation, and importance of body weight, temperature and stress. Aquaculture 2009, 295, 52-59. [CrossRef]

23. Zahl, I.H.; Kiessling, A.; Samuelsen, O.B.; Hansen, M.K. Anaesthesia of Atlantic halibut (Hippoglossus hippoglossus) Effect of pre-anaesthetic sedation, and importance of body weight and water temperature. Aquacult. Res. 2011, 42, 1235-1245. [CrossRef]

24. Santos, S.; Ghanawi, J.; Saoud, I.P. Effects of water temperature and body weight on anaesthetic efficiency in marbled rabbitfish (Siganus rivulatus). Aquacult. Res. 2015, 46, 928-936. [CrossRef]

25. He, R.; Lei, B.; Su, Y.; Wang, A.; Cui, K.; Shi, X.; Chen, X. Effectiveness of eugenol as an anesthetic for adult spotted sea bass (Lateolabrax maculatus). Aquaculture 2020, 523, 735180. [CrossRef]

26. Weber, R.A.; Peleteiro, J.B.; García Martín, L.O.; Aldegunde, M. The efficacy of 2-phenoxyethanol, metomidate, clove oil and MS-222 as anaesthetic agents in the Senegalese sole (Solea senegalensis Kaup 1858). Aquaculture 2009, 288, 147-150. [CrossRef]

27. Ghanawi, J.; Monzer, S.; Saoud, I.P. Anaesthetic efficacy of clove oil, benzocaine, 2-phenoxyethanol and tricaine methanesulfonate in juvenile marbled spinefoot (Siganus rivulatus). Aquacult. Res. 2013, 44, 359-366. [CrossRef]

28. Romaneli, R.d.S.; Boaratti, A.Z.; Rodrigues, A.T.; Queiroz, D.M.d.A.; Khan, K.U.; Nascimento, T.M.T.; Fernandes, J.B.K.; Mansano, C.F.M. Efficacy of benzocaine, eugenol, and menthol as anesthetics for freshwater angelfish. J. Aquat. Anim. Health. 2018, 30, 210-216. [CrossRef]

29. Matsche, M.A. Efficacy and physiological response to chemical anesthesia in wild hickory shad during spawning season. Mar. Coast. Fish. 2017, 9, 296-304. [CrossRef]

30. Öğretmen, F.; Gölbasi, S.; Kutluyer, F. Efficacy of clove oil, benzocaine, eugenol, 2-phenoxyethanol as anaesthetics on shabbout fish (Barbus grypus Heckel, 1843). Iran. J. Fish. Sci. 2016, 15, 470-478.

31. Filiciotto, F.; Buscaino, G.; Buffa, G.; Bellante, A.; Maccarrone, V.; Mazzola, S. Anaesthetic qualities of eugenol and 2phenoxyethanol and their effect on same haematological parameters in farmed European sea bass (Dicentrarchus labrax L.). J. Anim. Vet. Adv. 2012, 11, 494-502. [CrossRef]

32. Misawa, A.; Kada, S.; Yoshida, M. Comparison of the mode of action of three anesthetic agents, 2-phenoxyethanol, MS-222, and eugenol on goldfish. Aquacult. Sci. 2014, 62, 425-432.

33. Dziaman, R.; Klyszejko, B.; Hajek, G. The effect of MS-222 on the cardiac and respiratory function and behaviour of common carp, Cyprinus carpio L. during general anaesthesia. Acta. Ichthyol. Piscatoria. 2005, 2, 125-131. [CrossRef]

34. Uehara, S.A.; Andrade, D.R.; Takata, R.; Gomes Júnior, A.V.; Vidal, M.V. The effectiveness of tricaine, benzocaine, clove oil, and menthol as anesthetics for lambari-bocarra Oligosarcus argenteus. Aquaculture 2019, 502, 326-331. [CrossRef] 
35. Hedaya, M.A. Basic Pharmacokinetics, 2nd ed.; CRC Press: Boca Raton, FL, USA, 2012.

36. Kiessling, A.; Johansson, D.; Zahl, I.H.; Samuelsen, O.B. Pharmacokinetics, plasma cortisol and effectiveness of benzocaine, MS222 and isoeugenol measured in individual dorsal aorta-cannulated Atlantic salmon (Salmo salar) following bath administration. Aquaculture 2009, 286, 301-308. [CrossRef]

37. Tago, A.; Yokoyama, S.; Ishikawa, M.; Koshio, S. Pharmacokinetics of eugenol in Japanese flounder, Paralichthys olivaceus. J. World. Aquacult. Soc. 2018, 49, 780-787. [CrossRef]

38. Stenger, V.G.; Maren, T.H. The pharmacology of MS 222 (ethyl-m-aminobenzoate) in Squalus acanthias. Comp. Gen. Pharmacol. 1974, 5, 23-35. [CrossRef]

39. Guénette, S.A.; Uhland, F.C.; Hélie, P.; Beaudry, F.; Vachon, P. Pharmacokinetics of eugenol in rainbow trout (Oncorhynchus mykiss). Aquaculture 2007, 266, 262-265. [CrossRef]

40. Zhao, D.H.; Ke, C.L.; Liu, Q.; Wang, X.F.; Wang, Q.; Li, L.D. Elimination kinetics of eugenol in grass carp in a simulated transportation setting. BMC Vet. Res. 2017, 13, 346. [CrossRef] [PubMed]

41. Huang, S.; Xu, J.; Wu, J.; Hong, H.; Chen, G.; Jiang, R.; Zhu, F.; Liu, Y.; Ouyang, G. Rapid detection of five anesthetics in tilapias by in vivo solid phase microextraction coupling with gas chromatography-mass spectrometry. Talanta 2017, 168, 263-268. [CrossRef] [PubMed] 